THE FUKUSHIMA NUCLEAR POWER PLANT DISASTER AND THE FUTURE OF RENEWABLE ENERGY 
Copyright (C) 2018 by Cornell University

All rights reserved. Except for brief quotations in a review, this book, or parts thereof, must not be reproduced in any form without permission in writing from the publisher. For information, address Cornell University Press, Sage House, 512 East State Street, Ithaca, New York I4850.

First published 2018 by Cornell University Press

Printed in the United States of America

ISBN 978-I-50I7-2693-4

ISBN 978-I-50I7-2694-I (PDF) 


\title{
THE FUKUSHIMA NUCLEAR POWER PLANT DISASTER AND THE FUTURE OF RENEWABLE ENERGY
}

\author{
NAOTO KAN \\ PRIME MINISTER OF JAPAN (2010-2011) \\ Mario Einaudi Center for International Studies \\ Distinguished Speaker Series
}

March 25, 2017

Cornell University

CORNELL GLOBAL PERSPECTIVES

Mario einaudi
Center for
International Studies

CORNELL UNIVERSITY PRESS

Ithaca 
Naoto Kan spoke at Cornell University as part of the Mario Einaudi Center for International Studies Distinguished Speaker Series. His public lecture was delivered in Japanese. The text was translated for publication by Brett de Bary. 
IT HAS NOW BEEN SIX YEARS since the accident at Japan's Fukushima Daiichi Power Plant. A year and a half after its occurrence, I published the book, My Nuclear Nightmare: Leading Japan Through the Fukushima Disaster to a Nuclear-Free Future, based on my experience as Prime Minister of Japan at the time of the accident. The English translation of this book has just been published by Cornell University Press and I am deeply grateful. The book offers an account of the situations I faced at the time of the accident, focusing especially on what I confronted during the week that began on March II, 20II. I would be very pleased if you find my account of what actually happened during this time instructive.

\section{The Great East Japan Earthquake and tsunami}

The Great East Japan Earthquake erupted without any warning at 2:46 in the afternoon of March II, 20II. At that moment, I was attending a meeting of the Audit Committee in our Diet's [Parliament's] Upper House. No sooner had the committee chair announced the recess of the session than I raced to the Crisis Management Center in the Prime Minister's office complex beside the Diet Building. There, reports about the earthquake and tsunami were pouring in in rapid succession. According to these initial reports, all nuclear power plants in areas where the earthquake had occurred had been shut down successfully.

In nuclear power plants, control rods can be automatically inserted between the fuel rods to halt a nuclear fission chain reaction. However, if earthquake damage makes it impossible to insert these rods, there is no way of halting the reaction and a meltdown will occur.

\section{How the accident at Fukushima Daiichi occurred}

Despite initial reassurances, about one hour after the earthquake we received another report which announced that the tsunami that followed 
the earthquake had disabled not only the electrical generators outside the Fukushima Daiichi plant, but also the diesel-fueled equipment intended for emergency back-up use. This meant there was a total loss of power at the plant.

Soon after, we received further news that the cooling system throughout the plant had shut down. I still remember the chill that ran down my spine when I heard this. I am not a specialist in nuclear energy, but as a university student I majored in applied physics and had gained knowledge of the fundamentals of the field. In a power plant, even when nuclear fission chain reactions have been stopped, the decay of nuclear fuel will continue to create massive amounts of heat for a considerable period. I knew that if the cooling systems were disabled there would be a meltdown.

\section{Dysfunction at the government's Nuclear Emergency Response Headquarters}

By Japanese law, in the case of a severe accident in which the cooling systems of a nuclear power plant have been disabled, a Nuclear Emergency Response Headquarters is to be set up with the Prime Minister as its head. The Nuclear and Industrial Safety Agency (NISA) within the Ministry of Economy, Trade, and Industry (METI) oversees this disaster headquarters. The reasoning behind this is that the Prime Minister, as a politician, is generally not a specialist in nuclear energy, so a system is in place for government officials who are experts to offer him support.

Therefore, after the accident occurred I immediately summoned the director-general of NISA to obtain his views on three questions. What was the nature of the situation we were facing? How was it likely to develop? What measures should be taken? As it turned out, his response made no sense to me and I could not grasp the gist of his explanations. When I asked him if he was an expert in nuclear energy, this director-general of the Nuclear and Industrial Safety Agency replied that he was a Tokyo University graduate with a degree in economics!

I was stunned by this answer. Of course, since METI also deals with economic policy, it is not surprising for an official to hold a degree in economics. But how can we make sense of the appointment of an economist 
to be director-general of an agency charged with responding to nuclear accidents? One can only conclude that the assignment of personnel within METI was based on the assumption that a severe nuclear accident would never occur in Japan. Two days later, government officers with expertise in nuclear energy transferred into NISA from other agencies and came to consult with me. It was only at that point that I was able to receive an informed assessment of the situation.

\section{Worsening impact of the accident}

Since many politicians and government officials have had experience in dealing with natural disasters like earthquakes and tsunami, they were able to propose response measures quite rapidly. However, there was not a single person among us who had previously dealt with what is classified as a "severe accident" at a nuclear power plant. I received words of advice from members of the Nuclear Safety Commission as well as from members of NISA. I had requested that the head of the Nuclear Safety Commission himself attend my meetings, but in the early moments, no information had arrived about the actual circumstances of the accident, and not a single person could shed light on what its consequences might be. At this stage, I had no choice but to start to set up an organization within my own office to gather information about the accident. My special advisers and executive secretary were at the heart of these activities.

\section{Implications of the accident grow more severe}

Over the course of the week following the accident, its consequences increased in gravity. First, after the emergency generators had been disabled by the initial impact of the tsunami, I received a request from TEPCO [the Tokyo Electric Power Company] to coordinate with them in the dispatch of power supply trucks to the site. Since the earthquake had left many highways impassable, I called on police to help with this task. When, at Io p.m. on the night of March II, the day of the earthquake, we finally succeeded in getting power supply trucks to the plant, we rejoiced. Yet before long, 
we received word that the plugs in the trucks could not be connected to the plant. Although we did not understand the problem, ultimately the power supply trucks were useless, and we could not restore power.

At midnight that same night, word arrived that steam pressure was building up inside the containment vessels [also called "containment buildings," these are lead structures enclosing a nuclear reactor and its fuel rods] in the Number One Reactor, and that it would be necessary to release pressure from the vessels. Since radioactive matter would be released together with the steam, however, there was a possibility of harming area residents.

The Nuclear Emergency Response Headquarters, which would be responsible for evacuating residents in such a situation, had received a request for permission to release the pressure. Let me explain that under ordinary conditions, radioactive material from power plants should never be released into the atmosphere. However, if the containment vessels were to burst because they were unable to withstand the pressure, a very large amount of radioactive material would be released all at once. In the view of the Nuclear Safety Commission, the venting of steam pressure was now necessary in order to prevent the vessels from bursting. On this basis, and in the final hours of the night of March II, we communicated to TEPCO our understanding that the venting would be carried out.

However, in the following several hours, the venting did not take place. Knowing that the chances of the containment vessels bursting were increasing with the delay, I asked the liaison officials from TEPCO headquarters (who had been sent to my offices) why the delay was taking place. The TEPCO officials told me they simply did not know. In other words, I realized at this moment that TEPCO headquarters itself did not have a precise grasp of the situation. It was then that I felt that I would need to speak directly to responsible people at the site of the disaster.

To clarify, TEPCO was responsible for managing the power plant where the accident had occurred. But I, as Prime Minister and head of the Nuclear Emergency Response Headquarters, bore responsibility for the evacuation of residents. I went to Fukushima because I felt that I would need to have an accurate knowledge of the situation at the power plant in order to determine the radius of evacuation. 
On the morning after the accident, I went by helicopter to talk directly with the responsible parties at the site. Although I was criticized by the media and the opposition parties for hastiness in absenting myself from the Prime Minister's office complex, I felt it was important to get an accurate view of what had happened. At the site, I was able to meet the plant manager, Masao Yoshida, and to speak with him. Mr. Yoshida was a straightforward man who made a favorable impression on me. His explanation of the situation was very clear: "Under ordinary circumstances the venting system is operated by a switch, but because the electrical power in the plant is out, this will have to be done manually. This is a risky job, because radiation levels near the valve that would need to be manipulated are very high. But, do or die, we'll get the job done."

I wished him good luck as I left the plant. I felt Mr. Yoshida was someone I could trust.

\section{Worst-case scenario}

The first week after the accident was a nightmare. More accidents occurred one after another. Although we only learned this from investigations later, by 6 p.m. on March II, the first day of the accident, a meltdown had occurred at the Unit I reactor. This was only three hours after the initial earthquake. At Io p.m. that night, we received reports from the site that water had overflowed the spent fuel rods. This was because no one had realized that the water gauge was malfunctioning.

On the following day, March I2, a hydrogen explosion occurred at the Unit I reactor. Another occurred at the Unit 3 reactor on March I4. On March I5, when I was at TEPCO headquarters, sounds of an explosion came from the Unit 2 reactor, and almost simultaneously there was a hydrogen explosion at the Unit 4 reactor.

When the accident first occurred, the United States government issued a directive requiring American citizens within a 50-mile (80-kilometer) radius of the Fukushima power plant to leave. Many European embassies in Tokyo closed down, and their personnel began to be moved to the Kansai area.

If all the reactors at the Fukushima power plant were to become dysfunctional, the entire plant, together with the cooling pools that contain 
spent fuel, would melt down in a matter of a few weeks or months, and massive amounts of radioactive material would be released. I understood that if this were to happen, an evacuation of all the people within a large area, including the city of Tokyo, would be unavoidable.

On March 22, about ten days after the earthquake, when cooling by water pumps had begun and I was feeling we had narrowly escaped the worst, I had my special advisor, Mr. Gōshi Hosono, convey a message to Dr. Shunsuke Kondō, the chair of the Japan Atomic Energy Commission. I requested that the commission conduct a scientific evaluation of the area that would have to be evacuated in the event of multiple "worst-case scenarios." This scientific study is what the media have referred to as "the Prime Minister's office's worst-case scenario." It came in the form of a document delivered to me on March 25 from Dr. Kondō entitled "Rough Sketch of a Contingency Plan for the Fukushima Daiichi Power Plant."

Dr. Kondō's was a highly technical document. It stated that, "If Unit I's containment vessel is destroyed by a hydrogen explosion, increased radiation levels would force the plant's workers to evacuate the site. It would then be impossible to and cool Units 2 and 3 with water. Radioactive material will be discharged by these reactors and by the spent fuel pools in Units I through 4, and there is the possibility that a forced evacuation would be required for an area within a I70-kilometer (I06-mile) radius of the site and a voluntary evacuation area of 250 kilometers (I55 miles), including Tokyo." Here was scientific confirmation, from a specialist, of my own worst nightmare! As I read it, a chill went down my spine.

The 250-mile radius around Fukushima included a large part of the Kantō region, containing the city of Tokyo; the population of this radius is about 50 million people. An evacuation on that scale would be necessary. Dr. Kondō also calculated that, based on the amount of time necessary for radioactive material to decay on its own, it would take several decades before the evacuated areas were suitable for human habitation again. The evacuation of 50 million people from their homes for a period of several decades would have been an event without precedent in any country in the world!

While the stoicism with which the Japanese responded to the events of March II won admiration around the world, an evacuation of 50 million 
people would be a veritable hell. It would mean the upending of 50 million lives. Unlike moving to a new residence, evacuees flee leaving their belongings behind. What can they carry with them? Can they move as a family? Where will they go? And if they find a place to go, will they find jobs? Unimaginable hardship and confusion would ensue. Yet there was nothing "imaginary" about this forecast. We were a hair's breadth away from this actuality.

\section{The anguish of bearing ultimate responsibility}

For one week following March II, 20II, eastern Japan was on the verge of being occupied by an enemy: radiation. This enemy was not an invader from outside. While many Japanese did not think of it this way, this was an enemy the Japanese people had created for themselves. This was all the more reason they should bring the situation under control.

In order to cope with the Chernobyl crisis [in I986 in present-day Ukraine], the Soviet Union mobilized its army to extinguish fires by dropping 5,000 tons of sand and lead onto them from helicopters. Within a half a year of the disaster, the "stone sarcophagus" was constructed. It was reported that about 30 people, mainly firefighters, died from intense exposure to radiation during just the first ten days of working to extinguish fires. I have heard that military personnel, who were the next to be mobilized, also died in considerable numbers. However, if we were to do nothing about the reactors just because the work of dealing with them was dangerous, the risk of having even greater numbers of victims would be very high.

Faced with the actuality of the nuclear accident that had occurred at Fukushima Daiichi, I had no one but myself to turn to in thinking about these issues. Knowing that in the worst-case scenario people might die, could I ask them to go to the plant to help? I resolved that it was I, as Prime Minister, who would have to make this excruciating judgment. As I will describe, it was when I arrived at the TEPCO headquarters shortly after 5 a.m. on March I5, 20II, that this dire question confronted me in all its reality. 


\section{TEPCO's retreat and the consolidated headquarters}

At 3 o'clock in the morning of March I5, as I was taking a short nap in the Prime Minister's offices, my executive secretary awakened me to announce the arrival of the Minister of Economy, Trade, and Industry, Mr. Banri Kaieda. He told me that he had been informed by TEPCO's president, Masataka Shimizu, that TEPCO wished to allow its employees to leave Fukushima Daiichi.

One cannot fault Mr. Shimizu, as president of TEPCO, for wanting to allow his employees to leave a plant that had become highly dangerous. Yet, I had to ask what would become of the plant if these employees left. Key TEPCO personnel who knew how to operate the plant could not be replaced. Abandoning the reactors would mean that the situation would worsen in a matter of hours. Fuel would not be consumed, a meltdown would take place, and radioactive materials would start to be released into the environment. The increased damage resulting from this was incalculable.

The discussions over whether or not TEPCO would abandon the site continued through the night of the I4th until dawn on March I5. The import of that possibility was clear, however. If the ten reactors and II spent fuel pools were abandoned, Japan itself would be decimated.

My view was that to abandon the site was unthinkable. This view extended not only to TEPCO, but also to the Japan Self-Defense Force, the fire department, and the police. In ordinary circumstances, this would be asking too much from a private corporation. But TEPCO was the party responsible for the accident, and the nuclear reactor at the Fukushima plant could only be operated by TEPCO technicians. Without them, there was simply no way to bring the situation under control. For these reasons, I could not allow TEPCO to withdraw, even if it meant putting lives at risk.

In order to get TEPCO to join forces with the government, I concluded that it would be necessary to set up a joint command center staffed by both, and located at the TEPCO headquarters. And yet even on the grave question of TEPCO's requested withdrawal, we did not have smooth communication. Communication problems could very well be fatal to the process of trying to come up with a strategy for containing the disaster. I therefore called Mr. Shimizu to my offices. “TEPCO's withdrawal is not 
an option," I told him. I proposed that we set up an Integrated Response Center in TEPCO's offices, and he agreed.

In order to launch the Integrated Response Center, I went to TEPCO's headquarters at 5:30 in the morning on March I5. Since I assumed that the plan to withdraw from the plant reflected the view, not only of President Shimizu, but also of the CEO and other executives, it was my intention personally to try to persuade them to drop the plan. Summoning all the strength I could muster, I addressed them as follows:

More than anyone, you know the gravity of the situation we are in. There is a need for the government and TEPCO to strategize together, in real time. I will be the director, and Minister Kaieda and President Shimizu will be the deputy directors. I'm not just concerned about Unit 2. If we abandon Unit 2, what will happen to I, 3, 4, 5, and 6 ? And what will happen to the Fukushima Daini plant [a sister plant about ten kilometers (six miles) to the south]?

If we withdraw, within months all the reactors and nuclear waste will further deteriorate, resulting in the spread of radiation. It would be two or three times the size of Chernobyl, equal to ten or 20 reactors.

Japan will cease to exist if we don't risk our lives to bring this situation under control. We cannot withdraw quietly and watch from afar. If we were to do that, it would not be out of the question for a foreign country to come along and take our place.

You are all party to this, so I ask you to put your lives on the line. There is nowhere to run. Communication is slow, inaccurate, and often mistaken. Don't become dispirited. Provide the information that is needed. Take in what is happening now, but also look five hours, ten hours, a day, a week ahead, and act accordingly. It doesn't matter how much it costs.

No one can do this but TEPCO. When Japan is at risk of failure, withdrawal is out of the question. Mr. Chairman and Mr. President, prepare yourselves. Employees who are over 60 should go to the site. I, too, will work with this resolve. Withdrawal is out of the question. If you withdraw, TEPCO will inevitably fail.

I am repeating this speech for you based on notes taken by one of my staff members who attended the meeting. 


\section{Damage to the Unit 2 reactor}

At 6 o'clock in the morning of March I5, shortly after I had visited TEP$\mathrm{CO}$ headquarters to urge them not to withdraw, but to do everything in their power to bring the situation under control, I received a report from the Onsite Response Headquarters in Fukushima. Sounds of a blast were coming from some place near the Unit 2 reactor's suppression chamber. At the same time, the internal pressure in the containment buildings had reached the same level as the external pressure [which could lead to an explosion]. A hole was visible in one part of the suppression chamber.

Later investigations revealed that the source of the greatest radioactive emissions during this period had been the Unit 2 reactor. Had the unit's entire containment vessel been destroyed at that time, the possibility that my worst-case scenario would unfold was very high. It was, in fact, precisely because pressure in the Unit 2 containment building had dropped that we were able to pump water into the reactor.

\section{Counterattack}

Once the Integrated Response Center had been established at TEPCO's headquarters, communications between TEPCO and the government gradually grew more efficient. In the case of draining water from the spent fuel-rod pools, for example, we were able greatly to improve the system for cooperation between the Self-Defense Force and the police.

It was on March I6, the day after the Integrated Response Center was set up, that the Self-Defense Force was able to use helicopters to bring in water to be pumped into the spent fuel-rod pools, the first move forward in a counterattack against the relentless assault of radioactivity released by the accidents. Because a high level of radioactivity was being emitted into the atmosphere above the plant that day, on March I7 we brought in water by helicopter and commenced a life-or-death battle to get water into the plants. It was at this juncture that a wave of determination swept across the ranks of the Self-Defense Force, firefighters, and police to save Japan at the risk of their own lives.

Moreover, a reduction of pressure in the Unit I, 2, and 3 containment vessels had made the pumping in of water possible. As a result, it became 
possible to cool the nuclear fuel and gradually to reduce the heat it produced, stabilizing each of the reactors.

\section{By the grace of the gods}

As I have said, if venting the Unit 2 reactor had been delayed and pressure had risen within its containment vessel, explosions would have erupted that shattered the entire reactor like a balloon and we would have confronted my worst-case scenario. We escaped this only because the containment vessel was not destroyed, but survived with partial damage.

It was due to the heroic efforts of the TEPCO employees, the SelfDefense Force members, firefighters, and police, that we escaped the worst-case scenario. However, it was not for this reason alone. I cannot help feeling that we escaped, as they say, "by the grace of the gods."

Several lucky accidents came into play. One was that the Unit 4 reactor happened to have water in its spent fuel rod pool. Because of a delay in construction work, the upper part of this reactor happened to have been filled with water on the day of the accident. It is thought that the wooden partition between the upper level and the pool below warped that day, allowing water from the one into the other. Had there been no water flowing into the pool at the time, the spent fuel rods that were being transferred into the pool would have undergone meltdown, and there would have been no way to avert the worst-case scenario.

Thanks to this good fortune, we escaped the worst, and I never had to confront a situation that required formulating a concrete evacuation plan. The "50 million person evacuation simulation" that had been constantly playing itself out in my mind came to a stop. Nevertheless, that worst-case scenario occupies a part of my mind to this very day.

\section{The cause of the accident}

Why did the accident happen? The direct cause was the impact of the March II earthquake and tsunami that caused a total loss of power at the Fukushima Daiichi Nuclear Power Plant. Nevertheless, Japan is a country 
that has experienced numerous earthquakes, and been inundated by tsunami any number of times.

The accident occurred because the plant was built without paying adequate attention to these factors.

The Fukushima plant was designed to be built on a bluff overlooking the Pacific Ocean, 35 meters above sea level. However, when the reactors were constructed, earth was removed from the bluff to bring it down to an elevation of io meters above sea level. Had the reactors been located at 35 meters above sea level, the tsunami would not have reached them and the accident would not have occurred. The elevation was lowered to reduce the cost of electricity needed to pump in water from the ocean for cooling purposes.

It is also said that, several years before the accident, researchers at TEP$\mathrm{CO}$ had noted the possibility of a I7-meter tsunami hitting the plant. But TEPCO courted disaster by never formulating a contingency plan. At the present time, responsibility for the accident is being adjudicated in court.

\section{Reviewing our basic energy plan}

Prior to the Fukushima accident, Japan had provided for 30 percent of its energy needs through nuclear energy, and had planned to increase this to 50 percent by 2030. After the accident, I called for a review of the Basic Energy Plan that had recommended this increase, with the aim of reversing Japan's course in the direction of nuclear-free energy. Furthermore, I requested that Chūbu Electric halt operation of the Hamaoka Power Plant, which was located above an earthquake hypocenter, at the junction of two tectonic plates. My request was granted.

To help replace nuclear energy, I also introduced a system developed in Germany 20 years ago for establishing fixed prices for the purchase of energy generated from renewable sources, which would make it possible to expand the use of renewable energy. When I resigned as Prime Minister in September 20II, and was replaced by Prime Minister [Yoshihiko] Noda (a member, like me, of the Democratic Party of Japan), we resolved to reduce Japan's dependence on nuclear energy to zero by 2030 . 
However, the Democratic Party regrettably suffered a major defeat in the 2012 elections, while the LDP [Liberal Party of Japan] saw a resurgence of political power. The LDP decided to maintain a nuclear energy supply of 20 to 22 percent. Today, they are gradually restoring 44 reactors to operation. However, the Japanese population at large is against this policy, and in a number of cases courts have stopped orders to restart the plants. For this reason, only three nuclear power plants are operational in Japan today.

\section{The situation at Fukushima today}

The situation at the Fukushima power plant has still not yet been brought under control. More than I0०,००० people still live as evacuees. Among the reactors at the plant, Units I, 2, and 3, have had meltdowns, and water is still being pumped in to cool the nuclear debris. Some of this water, having been contaminated by radiation, has been leaking out from the containment vessels.

Following the example of Three Mile Island [a U.S. nuclear power plant that suffered a partial meltdown in I979], TEPCO and METI have come up with a plan to complete the collection and incineration of the radioactive debris over about a 40 -year period. However, I doubt whether this plan is feasible. Even at Three Mile Island, where the reactor's pressure vessels were left intact, debris had accumulated in the vessels. It was for this reason that a submersion method was used at Three Mile Islandthat is, the pressure vessels were filled with water-to block the emission of radiation, allowing the debris to be extracted.

In the case of Units I, 2, and 3 at Fukushima, however, the pressure vessels have been melted by heat and have holes in them. This caused debris to be scattered throughout the containment vessels. The radiation levels are so high inside that even one minute of exposure is lethal. To deal with the debris would require flooding the entire containment vessel, but the holes make this much more difficult to do than it had been at Three Mile Island.

At Chernobyl, a giant metal dome has been placed over the No. 4 reactor because, even after the passage of 30 years, radiation continues to leak from the stone sarcophagus. But there is still no plan at all for removing 
debris in Chernobyl. My guess is that the process at Fukushima will take more than Ioo years.

\section{Energy conservation and renewable energy}

As a result of the Fukushima accident, interest in matters related to energy has been heightened in Japan, and the situation surrounding energy use continues to change. Energy consumption in general in Japan now is down by io percent from its 2010 levels, prior to the Fukushima accident. People have a greater awareness of the importance of conserving energy, and this has resulted in measures undertaken at workplaces, large buildings, and private residences to reduce energy use.

In private homes, for example, it is becoming more common for people to install two or three layers of glass in their windows to conserve heat, and the number of households that have reduced their heating expenses to zero by installing solar panels on rooftops is growing. In 2013, I had my own home converted to an energy-saving home. By installing a 5-kilowatt solar panel on the roof, I now have a negative balance on my energy bills, and my heating bills are zero.

\section{The introduction of FIT and expansion of renewable energy}

Although many countries had increased their use of wind and solar energy before the Fukushima accident, in Japan at the time water-generated electrical energy accounted for only io percent of electrical energy used, and the use of other renewable sources of energy had not been promoted at all. This was because the vested interests in nuclear energy have had a great deal of power, and were able to suppress the development of renewable energy sources.

I came to believe in the necessity of encouraging the use of renewable sources—solar power, wind power, biomass_as a means of ending our reliance on nuclear power and fossil fuels.

Thus, three months after Fukushima, I took as my last task as Prime Minister the job of proposing to the Diet a bill for the establishment of a FIT [“feed-in-tariff"] system in Japan. [A FIT allows consumers generating 
renewable energy to be paid for feeding energy back into the power grid.] Since the introduction of the FIT system, the use of renewable energy, and especially solar power, has grown in Japan. By 20I5, solar energy generators in every prefecture were producing an amount of energy equal to that of five nuclear reactors. We expect that by 2020 , this will exceed the production of ten nuclear reactors.

\section{Combining agriculture and forestry with renewable energy generation}

In recent years, the possibility of combining farming with solar energy production has attracted attention in Japan. The country's plains are dotted with wide swaths of rice paddies. Yet the population in rural areas has declined, because rice prices have fallen and farming the paddies no longer generates sufficient income. In the past few years, however, methods have been developed for cultivating rice and vegetables while generating solar power, and these are attracting interest. For example, by implementing a practice called "solar sharing," farmers can install posts about three meters high in rice paddies and vegetable gardens, and use them to support solar panels at regular intervals. In this way, sunlight can be "shared" between crops and the panels. If this practice spreads in Japan, which has 4,600,000 hectares of agricultural land, the country could supply over half of its energy from farmland.

\section{Nuclear reactors in other countries}

In concluding my talk, I would like to introduce a few thoughts about nuclear power in countries I have been invited to visit.

Within a few months of the Fukushima accident, Germany decided to close down all of its nuclear plants by 2020 . In truth, I think Japan should be the first nation to reduce its use of nuclear energy to zero, but regrettably, it appears that this will not happen.

The first group to invite me to visit after the events of Fukushima was a citizens' group in California opposing restarting the San Onofre Nuclear Generating Station. I participated in a symposium there with Gregory 
Jaczko, who had been serving as the chair of the U.S. Nuclear Regulatory Commission at the time of the Fukushima accident. A few days later, Southern California Edison, owners of the plant, decided to decommission it. In the United States, nuclear power plants tend to be fewer on the West Coast, which is prone to earthquakes, and more numerous on the East Coast. Yet even in America, closings of nuclear power plants are outnumbering the construction of new ones, leaving a total of Ioo reactors in operation.

Following my visit to California, I was invited by anti-nuclear groups to visit Korea, Poland, the UK, and Taiwan. Taiwan decommissioned its newly constructed No. 4 reactor, and has resolved to move to zero reliance on nuclear power by 2025. Even in France, which matches the United States in the scale of its development of nuclear energy, Prime Minister Hollande publicly vowed to reduce the proportion of energy supplied by nuclear power plants from 75 percent to 50 percent, and cut back on the construction of new plants.

A chief reason for this reduction is that costs have risen, pushing the price of electricity generated by nuclear power plants above that generated from renewable sources. Nuclear energy has become less profitable. In England, for example, the government has approved the closing down of older nuclear power plants and approved the building of new ones. But it has proven difficult to raise funds from the private sector to support the new construction, so companies are turning to the government for assistance.

\section{Energy independence for all nations}

Scientists have calculated that the amount of energy radiated from the sun to the earth is I0,000 times greater than the energy used by the earth's human population. By this logic, if humans could effectively harness even one-thousandth of that power, it would be sufficient to satisfy their needs for electricity and heat. If we made use of the technologies available to us today, almost every nation in the world would be able to produce enough energy from renewable sources like wind and solar power to satisfy its energy needs. 


\section{NAOTO KAN}

If every nation in the world could satisfy its own energy needs, struggles for resources among nations-like the global competition for oilwould no longer arise.

The use of renewable, natural energy, and the end of reliance on nuclear energy and fossil fuels, can open a path to a peaceful world. It is my intention to commit myself without respite toward the achievement of this goal. 


\section{ABOUT NAOTO KAN}

Naoto Kan (born October Io, I946) was prime minister of Japan from June 2010 to September 20II. He has also served as deputy prime minister, finance minister, health minister, and national strategy minister.

The son of a corporate employee in the southern prefecture of Yamaguchi, Kan graduated with a degree in physics from the Tokyo Institute of Technology, where he was involved the student movement, then worked for a patent firm.

In I980, after three unsuccessful attempts, he won a seat in parliament as part of the tiny Social Democratic Federation. He served as health minister under a coalition deal with the Liberal Democratic Party (LDP) in the mid-I990s, becoming widely known after he exposed a scandal involving HIV-contaminated blood products.

He played a leading role in the formation of the Democratic Party of Japan (DPJ), which helped sweep the LDP from power in September 2009. Kan became prime minister after the resignation of fellow Democratic Party member Yukio Hatoyama in 20I0. He inherited a divided parliament, a stagnating economy, and massive public debt. He resigned less than six months after the Fukushima disaster.

\section{ABOUT THE EINAUDI CENTER}

The Mario Einaudi Center for International Studies was established in I96I to enhance Cornell's research and teaching about the world's regions, countries, cultures, and languages. In I990 it was named for its founding director, the political theorist Mario Einaudi. Today the center houses area studies and thematic programs; organizes speaker series, conferences, and events; provides grants and support to faculty and students; and brings together scholars from many disciplines to address complex international issues. 